\section{MEDICINE CABINET}

\section{How to treat influenza and colds}

\section{INFLUENZA}

The impact of influenza is often underestimated. In the United States, about 110,000 people are hospitalized and between 20,000 and 40,000 deaths are attributed to influenza each year. ${ }^{1}$ Elderly people and those with medical conditions, such as cardiopulmonary diseases or compromised immunity, are especially vulnerable to influenza and its complications; more than $90 \%$ of the deaths related to influenza occur in people aged 65 or older. In addition, it has become apparent that the direct and indirect consequences of influenza on younger people are also substantial. ${ }^{1,2}$

Despite the availability of effective vaccines and antiviral agents, serious influenza infections continue to be a global threat because influenza viruses have the ability to change their antigenicity. Minor changes in surface glycoproteins often occur as a result of point mutations (known as antigenic drift); major changes in the genes encoding for these glycoproteins occur less frequently but may introduce pandemic strains (known as antigenic shift). ${ }^{3}$ Newly approved antiviral drugs and immunization strategies in development will hopefully provide broader methods of protection in the future.

\section{Influenza vaccine}

The influenza vaccine is the most effective strategy in preventing influenza and ameliorating its severity. However, despite the illness and mortality associated with influenza infections, the vaccine remains underutilized. ${ }^{4}$ About $60 \%$ of people aged 65 or older and less than $30 \%$ of people younger than 65 who are at high risk of developing complications from influenza are actually vaccinated. ${ }^{1,4}$

The effectiveness of the vaccine depends primarily on the antigenic match between the strains in the epidemic and the strains contained in the vaccine and on the age and immune status of those who are vaccinated. Each year the vaccine is formulated to contain the two type $A$ strains and one type B strain that have been predicted to be the most likely to circulate in the current season. When the match is close, influenza will be prevented in about $70 \%$ to $90 \%$ of healthy adults. ${ }^{1}$ Elderly people and certain immunocompromised people may develop lower antibody titers after vaccination and this may reduce the efficacy of the vaccine. Although the vaccine may not prevent development of infections in these patients, annual vaccination has been shown to effectively protect against the

\section{Summary points}

- About 110,00o people are hospitalized with influenza each year

- The influenza vaccine is the most effective strategy for preventing influenza and ameliorating its severity

- Amantadine and rimantadine can be used for prophylaxis and treatment of influenza $A$

- Zanamivir and oseltamivir can be used to treat both influenza $A$ and $B$

- The best treatments for colds remain resting and drinking fluids

more serious complications of influenza including hospitalization and death. ${ }^{5,6}$ Annual vaccination has also been shown to reduce the incidence of acute otitis media in children and to offer substantial benefits to healthy, working adults, including reduction in upper respiratory illnesses, work absenteeism, and physicians' visits. ${ }^{7,8}$ Vaccination of health care professionals is also effective in preventing influenza infections and may, more importantly, reduce transmission to vulnerable, high-risk patients. ${ }^{9}$ Recommendations for the use of the influenza vaccine are outlined in table 1 .

\section{Future developments}

A trivalent, live, attenuated intranasal vaccine is being evaluated and may soon be approved for use in the United States. Besides the ease of administration, an intranasally administered live vaccine may offer the advantage of eliciting specific mucosal immune responses. Induction of local immunity is thought to provide broader protection against influenza than that afforded by the inactivated vaccine. ${ }^{10}$ In a clinical trial, the intranasal vaccine was found to be $93 \%$ effective in preventing culture-positive influenza when administered in healthy children aged 15 to 71 months; a $30 \%$ reduction in febrile otitis media was also observed in the vaccinated children. ${ }^{11}$ The results of a trial evaluating this intranasal vaccine in healthy, working adults were recently published. ${ }^{12}$ Although illness with fever occurred at the same rate in both the treatment and placebo groups, vaccination significantly reduced the incidence of severe febrile illness and febrile upper respiratory tract infection. Among those who were vaccinated 
Table 1 Guidelines for administering the influenza vaccine (adapted from recommendations of the Centers for Disease Control and Prevention ${ }^{1}$ )

\begin{tabular}{|c|c|c|}
\hline Target groups & Timing and administration & Contraindications \\
\hline People aged $\geq 65$ years & Vaccine may be given any time during flu season & $\begin{array}{l}\text { Previous anaphylactic reaction to vaccine, its } \\
\text { components, or to eggs }\end{array}$ \\
\hline $\begin{array}{l}\text { Adults and children who have chronic pulmonary or } \\
\text { cardiovascular disorders }\end{array}$ & $\begin{array}{l}\text { May be given concurrently with the } \\
\text { pneumococcal vaccine and with other routine } \\
\text { childhood vaccinations }\end{array}$ & $\begin{array}{l}\text { Previous vaccine-related Guillain-Barre } \\
\text { syndrome (vaccine may be justified in high risk } \\
\text { patients) }\end{array}$ \\
\hline $\begin{array}{l}\text { treatment with aspirin should receive the influenza } \\
\text { vaccine to reduce the risk of Reye's syndrome }\end{array}$ & febrile reactions* & \\
\hline $\begin{array}{l}\text { Women in the } 2 \text { nd or } 3 r d \text { trimester of pregnancy } \\
\text { during the influenza season } \\
\text { People who can transmit influenza to those who are } \\
\text { at high risk (for example, healthcare providers, } \\
\text { caretakers, household members) }\end{array}$ & $\begin{array}{l}\text { Should be administered intramuscularly: the } \\
\text { deltoid is the preferred site in adults, the } \\
\text { anterolateral aspect of thigh is preferred in } \\
\text { infants and younger children }\end{array}$ & \\
\hline $\begin{array}{l}\text { Other groups to consider include people infected } \\
\text { with HIV, travelers to regions with known } \\
\text { epidemics, and anyone who wishes to reduce their } \\
\text { risk of influenza illness }\end{array}$ & & \\
\hline
\end{tabular}

*At recommended doses, the immunogenicity and side effects of split and whole virus vaccines are similar in adults.

there was a significant reduction in the number of days of febrile illness, in work absenteeism, in health care utilization, and in the use of both antibiotics and over the counter drugs. These benefits were observed despite the fact that the vaccine formulation did not match the dominant variant strain (A/Sydney) circulating during the influenza season that was studied. These data suggest that the intranasal, live, attenuated vaccine may provide some cross-protection against drifted strains.

\section{Amantadine and rimantadine}

Two antiviral agents, amantadine and rimantadine, are available in the United States for preventing and treating influenza $\mathrm{A}$. They work by blocking the $\mathrm{H}^{+}$ion channel of the $\mathrm{M} 2$ protein membrane found on influenza $A$ viruses. This inhibits the acidification of the interior of the virus and ultimately prevents the release of viral RNA. ${ }^{13}$ These agents are important adjuncts in protecting unvaccinated people who are at high risk of exposure and in providing supplementary protection for those with diminished response to the vaccine. These agents have been used for seasonal prophylaxis, prophylaxis after exposure, and to control outbreaks in institutional settings. Both drugs are about $70 \%$ to $90 \%$ effective against influenza $\mathrm{A}$ when given prophylactically to adults or children. ${ }^{1}$ When used therapeutically within 48 hours of the onset of symptoms, amantadine and rimantadine can reduce the severity of symptoms and lessen the duration of influenza $A$ illness by approximately 24 hours. ${ }^{1,13}$ Information on doses and side effects is outlined in table 2.

Despite their efficacy, these antivirals are not widely used because they lack activity against influenza B viruses, carry significant risk for central nervous system side effects (especially amantadine), and can rapidly select for drug resistance during treatment. These shortcomings highlight the need to develop novel strategies to both prevent and treat influenza.

\section{Neuraminidase inhibitors}

Neuraminidase is a surface glycoprotein common to both types of influenza. Its enzymatic activities are essential for the release of virions from infected cells; it prevents viral aggregation at the host cell surface and may also inhibit inactivation of the virus by mucus in the respiratory tract. $^{14}$ Zanamivir (manufactured by GlaxoWellcome) and oseltamivir (manufactured by Roche) are new antiviral agents that selectively block the active site of neuraminidase. They are newly approved by the Food and Drug Administration for treatment of uncomplicated acute illness caused by influenza $A$ and $B$ viruses in patients who have been symptomatic for no more than 2 days.

The efficacy and safety of inhaled zanamivir in treating influenza A and B have been evaluated in three randomized, placebo-controlled clinical studies. Hayden et al conducted a trial at various centers in North America and Europe. ${ }^{15}$ Patients with influenza-like illness of less than 
Table 2 Anti-influenza drugs

\begin{tabular}{|c|c|c|c|c|}
\hline & Amantadine & Rimantadine & Zanamivir & Oseltamivir \\
\hline Indications & $\begin{array}{l}\text { Prophylaxis and treatment of } \\
\text { influenza A }\end{array}$ & $\begin{array}{l}\text { Prophylaxis and treatment of } \\
\text { influenza A }\end{array}$ & Treatment of influenza A and B & Treatment of influenza A and B \\
\hline $\begin{array}{l}\text { Treatment dose for } \\
\text { adults }\end{array}$ & $\begin{array}{l}100 \mathrm{mg} \text { orally twice a day for } \\
3-5 \text { days; start within } 2 \text { days of } \\
\text { onset of symptoms; reduce } \\
\text { dose in elderly patients (100 } \\
\text { mg orally daily); adjust dose in } \\
\text { patients with renal impairment }\end{array}$ & $\begin{array}{l}100 \text { mg orally twice a day for } \\
\text { 3-5 days; start within } 2 \text { days of } \\
\text { onset of symptoms; reduce } \\
\text { dose in elderly patients (100 } \\
\text { mg orally daily); adjust dose in } \\
\text { patients with severe renal or } \\
\text { hepatic dysfunction }\end{array}$ & $\begin{array}{l}2 \text { inhalations }(10 \mathrm{mg}) \text { twice a } \\
\text { day for } 5 \text { days; start within } 2 \\
\text { days of onset of symptoms }\end{array}$ & $\begin{array}{l}75 \mathrm{mg} \text { orally twice a day for } 5 \\
\text { days; start within } 2 \text { days of } \\
\text { onset of symptoms; reduce } \\
\text { dose in patients with clearance } \\
\text { creatinine }<30 \mathrm{ml} / \mathrm{min} \text { ( } 75 \mathrm{mg} \\
\text { orally daily) }\end{array}$ \\
\hline $\begin{array}{l}\text { Most common side } \\
\text { effects }\end{array}$ & $\begin{array}{l}\text { CNS excitation (such as } \\
\text { nervousness or anxiety); mild } \\
\text { GI side effects }\end{array}$ & $\begin{array}{l}\text { CNS excitation (but more } \\
\text { prominent with amantadine); } \\
\text { mild GI side effects }\end{array}$ & $\begin{array}{l}\text { Risk of bronchospasms in } \\
\text { patients with underlying } \\
\text { airway disease }\end{array}$ & $\begin{array}{l}\text { Mild GI side effects (nausea, } \\
\text { vomiting) }\end{array}$ \\
\hline Precautions & $\begin{array}{l}\text { Avoid concurrent } \\
\text { administration of CNS } \\
\text { stimulants, antihistamines, or } \\
\text { anticholinergic drugs }\end{array}$ & $\begin{array}{l}\text { Avoid concurrent } \\
\text { administration of CNS } \\
\text { stimulants, antihistamines, or } \\
\text { anticholinergic drugs }\end{array}$ & $\begin{array}{l}\text { Use with caution in patients } \\
\text { with airway disease; instruct } \\
\text { patient on use of inhalation } \\
\text { device }\end{array}$ & $\begin{array}{l}\text { Advise patients to take with } \\
\text { food to avoid Gl upset }\end{array}$ \\
\hline $\begin{array}{l}\text { Average wholesale } \\
\text { price for } 5 \text {-day } \\
\text { course* }^{*}\end{array}$ & $\$ 6.00$ (generic) & $\$ 19.00$ & $\$ 45.00$ & $\$ 53.00$ \\
\hline
\end{tabular}

CNS = central nervous system; $\mathrm{Gl}=$ gastrointestinal.

*In October 1999.

48 hours duration were randomized to receive zanamivir inhalation plus placebo nasal spray, zanamivir inhalation plus zanamivir nasal spray, or placebo inhalation plus placebo nasal spray. In patients with confirmed influenza, the median time until all major symptoms were alleviated was 1 day less in patients in the treatment groups compared with those in the placebo group. Similar benefits were observed in the intent-to-treat population. The greatest clinical benefit was achieved in patients presenting with fever at the time of enrollment and in those who began treatment within 30 hours of the onset of symptoms. In these subgroups, the median time until alleviation was 4 days in the treatment groups compared with 7 days in the placebo group. Similar results were observed in studies published subsequently. When initiated within 36 to 48 hours of the onset of symptoms, zanamivir shortened the time until the alleviation of symptoms by 1 to 1.5 days compared with placebo. ${ }^{16,}{ }^{17}$ Again, the most significant benefit was observed in patients who had a fever when they entered the study or who presented within 30 hours of the onset of symptoms. In the small subset of patients categorized as being at high risk (those aged 65 or older and those with respiratory, endocrine, or cardiovascular disorders), symptoms were alleviated 1.5 to 2.5 days earlier among those receiving zanamivir compared with those receiving placebo. Similar rates of efficacy have been observed with oseltamivir phosphate, an orally bioavailable prodrug of the neuraminidase inhibitor oseltamivir carboxylate. In two major trials, treatment with oseltamivir within 40 hours of onset of symptoms resulted in a 1.3 day reduction in the median time until symptoms im- proved. ${ }^{18}$ Transient mild to moderate nausea was associated with oseltamivir treatment.

The use of neuraminidase inhibitors for chemoprophylaxis is currently under evaluation. In a study of more than 1000 healthy adults, zanamivir given once daily for 28 days at the onset of a community outbreak was $67 \%$ effective in preventing influenza confirmed by laboratory analysis. No excess adverse events were observed with prolonged use of zanamivir in this study. ${ }^{19}$ The efficacy of oseltamivir for long-term prophylaxis has also been investigated in healthy adults. When administered daily for 6 weeks during local outbreaks, oseltamivir was $74 \%$ effective in preventing laboratory confirmed clinical influenza. ${ }^{20}$ Nausea was reported more frequently in patients receiving oseltamivir than in those people receiving placebo.

The newly approved neuraminidase inhibitors have generated renewed interest in influenza management. Besides having a wider spectrum of activity, these agents are much less likely to induce resistance and are generally well tolerated. Data suggest, however, that treating healthy adults with zanamivir or oseltamivir is only of modest benefit. Data are limited on treatment in elderly people and other high risk populations for whom prophylaxis and treatment would be of greatest benefit. Further studies will better define the role of these agents in regard to public health policy.

The window of opportunity for therapeutic intervention with these agents is narrow. Data do not support the initiation of treatment later than 2 days after the onset of symptoms. Since early initiation is crucial, patients should be counseled on the proper use of these drugs. This is 
particularly important for zanamivir, as delivery of the drug is dependent on the proper use of a hand-held, breath-activated inhalation device.

\section{THE COMMON COLD}

The common cold is a viral illness that affects adults an average of two to four times each year and affects children four to eight times a year. ${ }^{21}$ The rhinoviruses are the pathogens most commonly associated with colds. Although colds are generally mild and self-limiting the economic burden, in terms of visits to physicians, absenteeism from work, loss of productivity, and the cost of treatment, is great.

A definitive treatment for the common cold remains elusive. Treatment is primarily aimed at relieving symptoms. Most treatments are of limited efficacy and are not without side effects. The difficulty in finding a cure for the common cold lies in the fact that more than 200 different viruses may be responsible for the disease. Unlike the treatment of influenza, the development of a single vaccine that could target all the viral antigens is not feasible. Moreover, any new treatments would have to be highly efficacious, nontoxic, and extremely economical to be practical for treating this widespread disease. Pharmacologic modalities that block viral entry into the body and specific antiviral treatments are in development.

\section{Management of symptoms}

Resting and drinking fluids remain the standard treatments for colds. Many patients also use over the counter remedies. Each year in the United States, over $\$ 2$ billion is spent on preparations designed to treat the common cold. ${ }^{22}$ A critical review of clinical trials evaluating cold remedies available over the counter found some evidence to support the use of antihistamines, decongestants, and anticholinergic drugs in adults. ${ }^{23}$ The review did not find strong evidence to support the use of remedies aimed at preschool children. The literature does not support the use of nonsedating antihistamines (which lack anticholinergic properties) and antitussives, such as dextromethorphan, for managing cold symptoms. In general, recommendations for over the counter products should be tailored to address specific complaints to minimize side effects from multi-symptom formulations.

The inhalation of steam has also been prescribed frequently for treating colds because it was thought that local hyperthermia might inhibit viral replication and improve congestion. A recent study found that inhalation of hot, humidified air had no effect on viral shedding in experimentally induced colds caused by rhinoviruses. ${ }^{24}$ It is, however, an inexpensive and nontoxic option for those patients who find that it relieves their symptoms. ${ }^{21,25}$ Patient safety should always be considered when prescribing steam inhalation or the use of a steam vaporizer because of the risk of burns, especially in the young children with colds.

\section{Alternative treatments}

Despite the limited and conflicting evidence available in the literature, the use of alternative or natural remedies is increasing; this is reflected in the growing selection of products available and marketed for cold sufferers. Two of the most controversial and popular remedies are zinc lozenges and echinacea.

\section{Zinc}

Several mechanisms have been proposed by which zinc may be effective against the common cold. At a concentration of about $0.1 \mathrm{mmol} / \mathrm{L}$ in vitro, zinc prevents the formation of viral capsid proteins and thus inhibits replication of rhinoviruses. ${ }^{26}$ Zinc may also have immunomodulating properties and act by inducing the production of interferon. ${ }^{27}$ Evidence from clinical trials is inconsistent: several studies found a decrease in the duration of cold symptoms and several others showed a lack of benefit. $^{28}$ The discrepancy in efficacy may be attributed to the different doses and formulations used in the trials. It has also been suggested that certain formulations may have rendered the zinc ions inactive.

Overall, the results from studies that found a reduction in the duration of cold symptoms vary, making it difficult to recommend zinc lozenges. Although generally deemed safe for short-term use in adults, the costs of these products as well as the potential for side effects such as unpleasant taste, mouth irritation, and gastrointestinal disturbances should be considered. Patients should also be advised to avoid concurrent use of zinc lozenges when taking quinolone or tetracycline antibiotics because zinc ions may disrupt the absorption these antibiotics. ${ }^{23}$

\section{Echinacea}

Echinacea is another remedy gaining popularity in the United States for treating colds. This herb is purported to exert its action through nonspecific immunomodulatory properties. The species most commonly used for medicinal purposes include Echinacea purpurea, E pallida, and $E$ angustifolia. Despite the widespread use of echinacea, supporting data from well designed clinical trials are limited. If echinacea is used early in the course of infection it may decrease the severity and duration of acute respiratory infections. ${ }^{29,}{ }^{30}$ However, until the results of research with standardized dosages and formulations are available, a definitive recommendation about its use for the common cold cannot be made. Echinacea appears to be generally free of toxic side effects. ${ }^{31}$ However, it should be avoided by people with autoimmune disorders and by those receiving immunosuppressant drugs (because of a theoretical risk of nonspecific stimulation of the immune system). 
Use of this herb is also contraindicated in patients with progressive systemic diseases, such as tuberculosis and multiple sclerosis, in those who are HIV positive, and in people who are allergic to plants of the Asteraceae family. ${ }^{31,}{ }^{2}$

\section{Future developments}

Although various compounds have been shown to be active against rhinoviruses in vitro, their clinical efficacy has been disappointing. Recently, investigators have isolated a common cellular receptor responsible for cell attachment that is shared by most rhinovirus serotypes. The identification of this intercelluar adhesion molecule (ICAM-1) provides a target for pharmacological intervention. Specifically, a recombinant, soluble form of the glycoprotein, known as tremacamra, has been developed to inhibit viral adhesion and thereby prevent subsequent colds. When tremacamra was administered intranasally either 7 hours before or 12 hours after viral challenge, it significantly lessened the severity of experimentally induced rhinovirus colds compared with placebo; however, a trend toward a reduction of clinical infections with tremacamra did not reach statistical significance in a pooled analysis of four studies in humans. ${ }^{33}$ Another novel antiviral agent, pleconaril, is under investigation for use in treatment against infection with picornaviruses (enteroviruses and rhinoviruses). Preliminary results in humans indicate that treatment with pleconaril significantly reduces the time until symptoms resolve. ${ }^{34}$

\section{EDUCATING PATIENTS}

Because of the increase in bacteria resistant to antibiotics in the community (for example, the emergence of Streptococcus pneumoniae resistant to penicillin and cephalosporin), antibiotics should be used judiciously in the ambulatory care setting. One study found that more than $50 \%$ of adult patients diagnosed with colds and upper respiratory illnesses were prescribed an antibiotic. ${ }^{35}$ Similar rates of inappropriate prescribing were also identified in the treatment of children. ${ }^{36}$ Prescribing habits need to be changed. Efforts should also be made to educate patients about viral respiratory infections and the ineffectiveness of antibiotics for treating these illnesses.

References

1 Centers for Disease Control and Prevention. Prevention and control of influenza: recommendations of the advisory committee on immunization practices (ACIP). MMWR 1998;48(RR):1-28.

2 Neuzil KM, Reed GW, Mitchel EF, et al. Influenza-associated morbidity and mortality in young and middle-aged women. JAMA 1999;281:901-907.

3 Kaiser L, Hayden FG. Hospitalizing influenza in adults. Curr Clin Top Infect Dis 1999;19:112-134.

4 Mossad SF. Underused options for preventing and treating influenza. Cleve Clin J Med 1999;66:19-23.

5 Gross PA, Hermogenes AW, Sacks HS, et al. The efficacy of influenza vaccine in elderly patients: a meta-analysis and review of the literature. Ann Intern Med 1995;123:518-527.

6 Mullooly JP, Bennett MD, Hornbrook MC, et al. Influenza vaccination programs for elderly persons: cost effectivness in a health maintenance organization. Ann Intern Med 1994;121:947-952.
7 Heikkinen T, Ruuskanen O, Waris M, et al. Influenza vaccination in the prevention of acute otitis media in children. Am J Dis Child 1991;145:445-448.

$8 \mathrm{Nichol} \mathrm{KL}$, Lind A, Margolis KL, et al. The effectiveness of vaccination against influenza in healthy, working adults. $N$ Engl J Med 1995;333:889-893.

9 Wilde JA, McMillan JA, Serwint J, et al. Effectiveness of influenza vaccine in health care professionals. JAMA 1999;281:908-913.

10 Cox NJ, Subbarao K. Influenza. Lancet 1999;354:1277-1282.

11 Belshe RB, Mendelman PM, Treanor J, et al. The efficacy of live attenuated, cold-adapted, trivalent, intranasal influenzavirus vaccine in children. $N$ Engl J Med 1998;338:1405-1412.

12 Nichol KL, Mendelman PM, Mallon KP, et al. Effectiveness of live, attenuated intranasal influenza virus vaccine in healthy, working adults. JAMA 1999;282:137-144.

13 Nicholson KG. Use of antivirals in influenza in the elderly: prophylaxis and therapy. Gerontology 1996;42:280-289.

14 Dunn CJ, Goa KL. Zanamivir: a review of its use in influenza. Drugs 1999;58:761-784.

15 Hayden FG, Osterhaus AD, Treanor JJ, et al. Efficacy and safety of the neuraminidase inhibitor zanamivir in the treatment of influenzavirus infections. N Engl J Med 1997;337:874-880.

16 MIST Study Group. Randomized trial of efficacy and safety of inhaled zanamivir in treatment of influenza A and B virus infections. Lancet 1998;352:1877-1881.

17 Monto AS, Fleming DM, Henry D, et al. Efficacy and safety of the neuraminidase inhibitor zanamivir in the treatment of influenza $A$ and B virus infections. J Infect Dis 1999;180:254-261.

18 Tamiflu Product Information. Roche Pharmaceuticals. Nutley, NJ. October 1999.

19 Monto AS, Robinson DP, Herlocher ML, et al. Zanamivir in the prevention of influenza among healthy adults. JAMA 1999;282: 31-35.

20 Hayden, FG, Atmar RL, Schilling M, et al. Use of the selective oral neuraminidase inhibitor oseltamivir to prevent influenza. JAMA 1999;341:1336-1343.

21 Mossad SF. Treatment of the common cold. BMJ 1998;317:33-36

22 Garland ML, Hagmeyer KO. The role of zinc lozenges in treatment of the common cold. Ann Pharmacother 1998;32:63-69.

23 Smith MB, Feldman W. Over-the-counter cold medications. JAMA 1993;269:2258-2263.

24 Hendley JO, Abbott RD, Beasley PP, et al. Effects of inhalation of hot humidified air on experimental rhinovirus infection. JAMA 1994;271:1112-1113.

25 Tyrrell D, Barrow I, Arthur J. Local hyperthermia benefits natural and experimental common colds. BMJ 1989;298:1280-1283.

26 Geist FC, Bateman JA, Hayden FG. In vitro activity of zinc salts against human rhinoviruses. Antimicrob Agents Chemother 1987;31:622-624

27 Salas M, Kirchner H. Induction of interferon-gamma in human leukocyte cultures stimulated by $\mathrm{Zn}^{2+}$. Clin Immunol Immunopathol 1987;45:139-142

28 Jackson JL, Peterson C, Lesho E. A meta-analysis of zinc salts lozenges and the common cold. Arch Intern Med 1997;157:2373-2376.

29 Melchart D, Linde K, Worku F, et al. Immunomodulation with echinacea: a systematic review of controlled clinical trials. Phytomedicine $1994 ; 1: 245-254$

30 Barrett B, Vohmann M, Calabrese C. Echinacea for upper respiratory infection. J Fam Pract 1999;48:628-635.

31 Blumental M, ed. The complete German Commission E monographs: therapeutic guide to herbal medicines. Austin, TX: American Botanical Council, 1998.

32 Pepping J. Echinacea. Am J Health Syst Pharm 1999; 56:121-122.

33 Turner, RB, Wecker MT, Pohl G, et al. Efficacy of tremacamra, a soluble intercellular adhesion molecule 1, for experimental rhinovirus infection. JAMA 1999;281:1797-1804

34 ViroPharma Incorporated announces successful viral respiratory infection program with pleconaril -first clinical effect seen in patients with severe common cold [press release]. ViroPharma Inc. Exton, PA. July 13, 1999.

35 Gonzales R, Steiner J, Sande M. Antibiotic prescribing for adults with colds, upper respiratory tract infections, and bronchitis by ambulatory care physicians. JAMA 1997;278:901-904.

36 Nyquist, A, Gonzales R, Steiner J, et al. Antibiotic prescribing for children with colds, upper respiratory tract infections, and bronchitis. JAMA 1998;279:875-877. 